\title{
Incorporating Entrepreneurship skills into Chemistry and Related Curriculums
}

\author{
Baljit Ghatora* \& Robert Strutt \\ *Corresponding Author: B.Ghatora@kingston.ac.uk
}

Keywords: Entrepreneurship, Chemical \& Pharmaceutical industry, innovation

\begin{abstract}
With the ever increasing pace of change in the Chemical and Pharmaceutical Industry, universities need to be more aware of the skill set that employers are seeking in graduates. These skills often include risk taking, creative thinking and entrepreneurship; skills that are not naturally associated with chemistry-related curriculums. This research focusses on the authors' experiences of applying for strategic grants which underpin the dissemination of such skills, and explores how these were used as the basis for creating specific learning content for final year students. Students' experiences after completing assignments were gathered through an online survey and subsequent analysis identified areas for improvement in chemistry curriculums.
\end{abstract}

\section{Introduction}

The HM Government's "Building Our Industrial Strategy" Green Paper was released in January 2017 for consultation. It highlighted the challenges and weaknesses that the UK industries face and suggested areas of improvement required post-Brexit (HM government 2017). The Green Paper recognised that the UK produces a similar number of spin-off companies compared with US universities, when measured per unit of research funding, but far fewer patents are registered (BIS 2013; HEFCE Survey 2015). These statistics coupled with the desire for the UK to continue building on its strengths in research and development has meant that changes will soon be appearing on the horizon for increasing opportunities for innovation. Consequently, the authors believe that universities should be encouraged to develop more entrepreneurial graduates to take up some of the opportunities for innovation that may appear in the near future.

The Chemical and Pharmaceutical industry is rapidly changing, and literature has reported that employers within these industries look for graduates who are not only technically competent, but also have knowledge of how for-profit organisations function (Kerr et al 2005). Although employability is embedded into most higher education curriculums, employer surveys have indicated that there is a mismatch between the skills that employers say that their businesses need and the graduate skills coming through the higher education system. In the 2015 Survey of Employers (CBI) it was noted that $34 \%$ of businesses said that the quality of STEM graduates was not good enough and $46 \%$ said they lacked business and commercial awareness in the workplace. Equally in the 2013 Employer Skills Survey Report, the UK Commission for Employment and Skills (UKCES) reported that some graduates 'lacked experience of the working world or experience of life in general.' (BIS 2016; Windsor et al 2014). Employers' opinions of what they require from graduates also includes individuals who are capable of fulfilling organizational tasks effectively, and for graduates to be able to demonstrate "soft skills", not just subject knowledge, that allows them to compete at an international level, and to contribute to the development of business ideas, and organizational growth (Lowden et al 2011). 
According to the American Chemical Society taskforce review, there are unlimited opportunities for innovation and enterprise in the field of chemistry (ACS taskforce reviewGeorge Whitesides \& Joseph Francisco "Entrepreneurship + Innovation = Jobs"). The biggest challenges facing society currently are ones that could be tackled with the application of chemistry, for example chronic diseases. It is clear to see throughout the literature that there is an employer demand for graduates to have the correct "soft skills" that allow them to contribute towards innovation and enterprise (Rae 2007; 2010; Andrews \& Higson 2008). However, the higher education (HE) environment is not immediately conducive to graduates learning to deal with essential entrepreneurial attributes such as failure, (Chell 2013; Rae 2008) and to adapt their approach to ensure future improvements, because progression in $\mathrm{HE}$ is judged on academic success alone and is assessed in a variety of disparate assignments using different assessment modalities.

This research focuses on a final year module co-taught to Chemistry and Pharmaceutical Science students, which lends itself well to exploring real-life industrial opportunities. The students were able to apply their disciplinespecific knowledge in a holistic approach to a summative group assessment which addresses a specific business need. They are enabled the freedom to explore skills which are not naturally affiliated with Chemistryrelated course content, such as their entrepreneurship, communication and persuasive skills. This research explores the authors' recent successes of applying for knowledge transfer grants, and how these experiences have been used to create a final year assignment across the Chemistry and Pharmaceutical Science modules. It is envisaged that this new type of assignment will encourage students to reflect upon their graduate attributes and develop a holistic awareness about how industry operates.

\section{Methodology}

The students $(\mathrm{N}=108)$ were split into 18 groups of 6 students to each group. To enable students to gain a real life experience of working in a multidisciplinary team in industry the student cohort was split up equally so that each group had student representation from across the two degrees (Pharmaceutical Science and Chemistry). Initially a series of lectures, focussed on the business needs and departmental roles of a typical chemical and pharmaceutical company, were delivered on the jointly taught "Polymer and Industrial Chemistry" and "Topics in Pharmaceutical Science" modules. The lectures also gave students exposure to examples of various funding streams, pump priming grants and Innovate UK funding that could be applied for to introduce a new idea to the market. Subsequently students were presented with a final summative assignment with a clear learning outcome and assessment criteria associated with it. The assignment information provided is shown in figure 1.

The assignment required them to research into the current intraocular lenses available in the market and come up with an idea of synthesising a new type lens suitable for manufacture. The assignment was marked with a group mark and a small percentage contributed towards an individual element. (Students were required to clearly highlight the aspects that each group member contributed to.) This takes into account creativity, entrepreneurship, innovation and ability and initiative to explore new ideas.

After the assignment was submitted student feedback was gathered. An ethically approved (Kingston University Centre for Higher Education Research and Practice Ethics Panel) online survey, administered through Survey Monkey, was developed to gather student feedback to explore how the students handled this assignment, and the subsequent impact that it has had on their awareness of industry and their graduate employability. It will also inform us of any improvements which could be implemented in the next academic year. 


\section{Assignment brief}

A global leading intraocular lens manufacturer wishes to expand its market into Germany, and has put forward an expression of interest to University Research Groups in order to jointly apply for a Knowledge Transfer Grant.

Your research group at Kingston University will be applying for this Knowledge Transfer Grant. You must produce a bid that persuades the manufacturer to work with your research group. Your bid must include a scientific proposal that puts forward a strategic plan of bringing a new intraocular lens to market and takes into account the roles of the various departments within the company that would require being involved in the manufacturina and release of the product to the market.

Figure 1 Assignment Brief

\section{Results and Discussion}

The assignment was marked online using marking criteria. The average group assignment mark was $63 \%$, with an average individual mark of $60 \%$. Feedback was provided to the group and also individually for the elements that each student contributed to. The survey was sent to all students that submitted the assignment and, although the response was low $(n=16)$, some interesting data emerged. In order to assess the students understanding of entrepreneurship they were initially asked to choose up to three skills they think best describes entrepreneurship (Figure 2).

It is apparent that students are aware that innovation and problem solving are inherently associated with entrepreneurship and they also feel that those skills are important within the chemical and pharmaceutical industries (Figure 3), but did not explicitly make the link to enterprise. Alongside this they do not feel that financial awareness is a sought-after skill within the chemical and pharmaceutical industries. This could be because there is not enough taught on the degree programmes on financial investment and awareness as $86 \%$ (57\% "partially" and 29\% "not at all" responses grouped together) of students indicated that the degree had not increased their employability in regards to financial awareness and investment.

Interestingly, although $50 \%$ of students felt that creative thinking was a skill that describes entrepreneurship, only $25 \%$ of students thought that it was important in the chemical and pharmaceutical industries, and an alarming $77 \%$ of students thought their degree had not helped them increase their creative thinking ability. One of the key attributes of an entrepreneur is idea generation and creation (Chell et al, 2013) therefore it is important that students are provided with this opportunity within their degrees. This is even more important considering that $50 \%$ of students enjoyed this aspect of the set assignment, as well as $50 \%$ who enjoyed researching into new business ideas (Figure 4). Some of the positive comments that students provided indicated that they enjoyed "teaching others", and being able to argue for or justify a point. These were also identified as entrepreneurial attributes in a study investigating the impact of entrepreneurship teaching on the employability of scientists and engineers (O'Leary, 2012).

When students were asked about their degree classifications, and whether they felt that their final grade reflects the skills they may have acquired across the course of the degree, surprisingly $56 \%$ of students felt the grade they achieved was representative of the skills they acquired, with only 19\% agreeing that skills are learnt separately from the final grade and cannot be demonstrated through a degree classification. In contrast to this, some literature suggests that employers tended to prefer undergraduates with a second class degree who were capable of demonstrating a range of transferable enterprise skills, in favour of postgraduates lacking such skills (Schofield, 1996). 


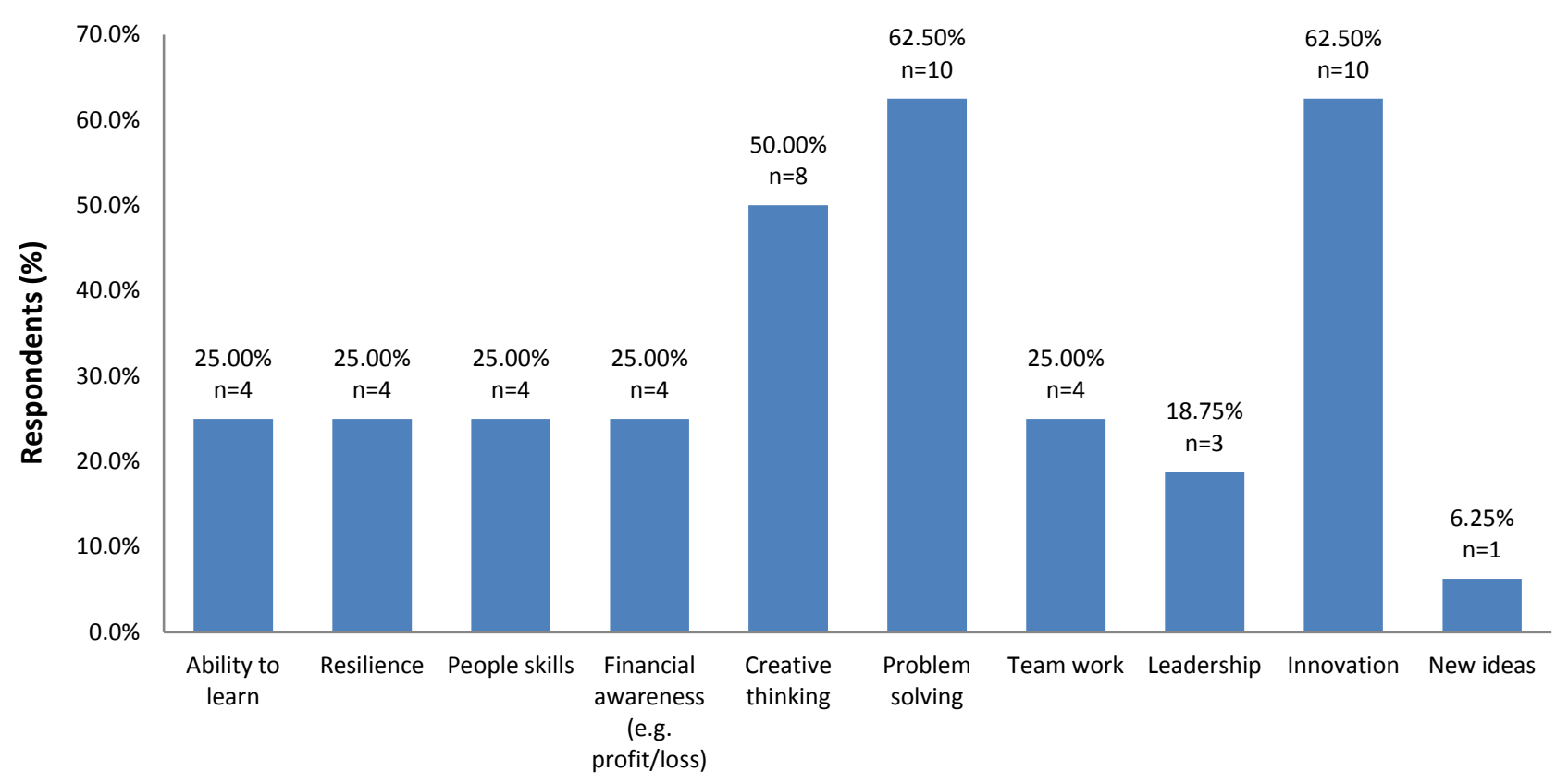

Skills that Describe Entrepreneurship

Figure 2 Which of the following skills do you think best describes entrepreneurship? (Choose up to 3) (Total $n=16)$

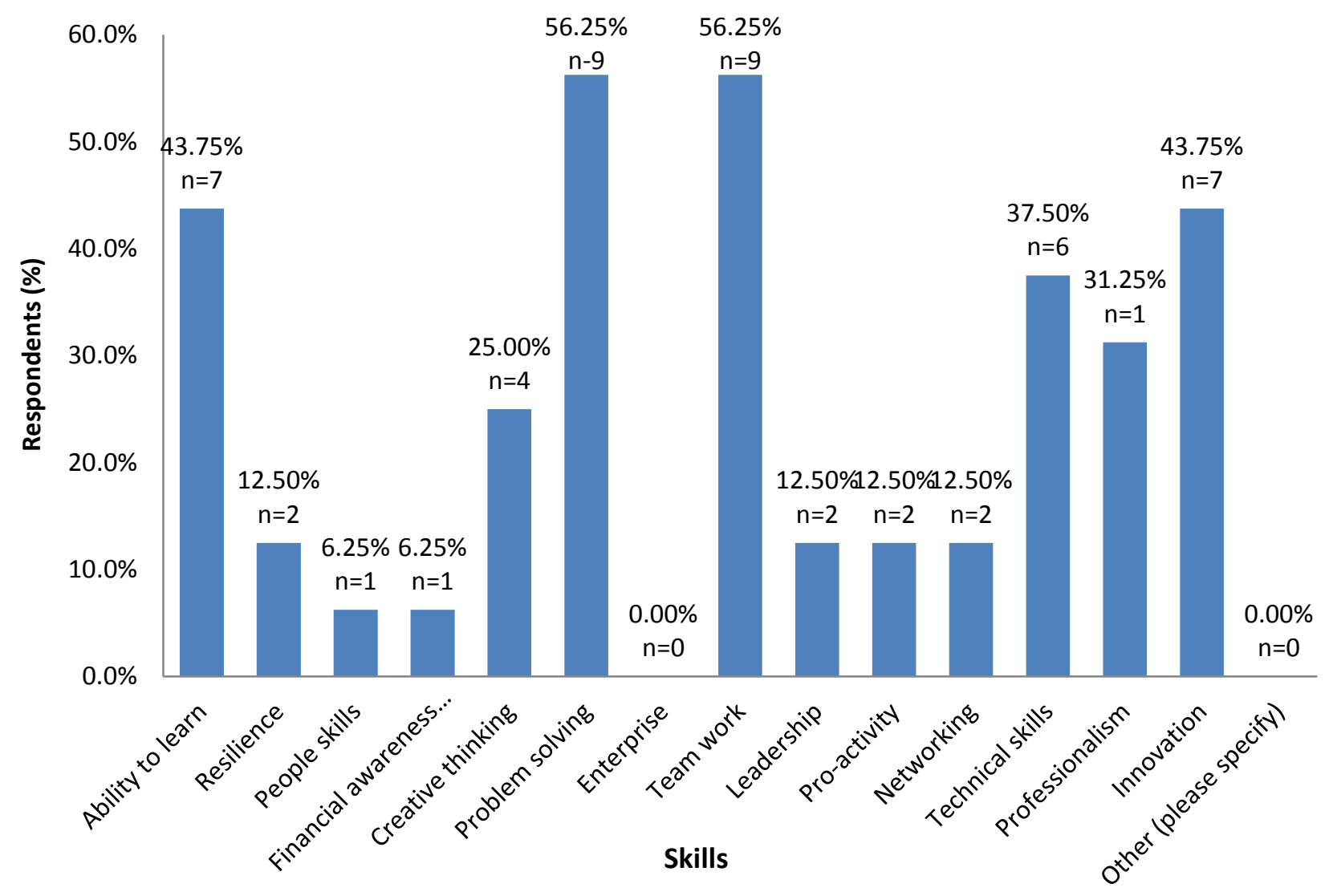

Figure 3 Which of the following skills do you think are important within the chemical and pharmaceutical industry? (Choose all that apply) (Total $n=16$ ) 


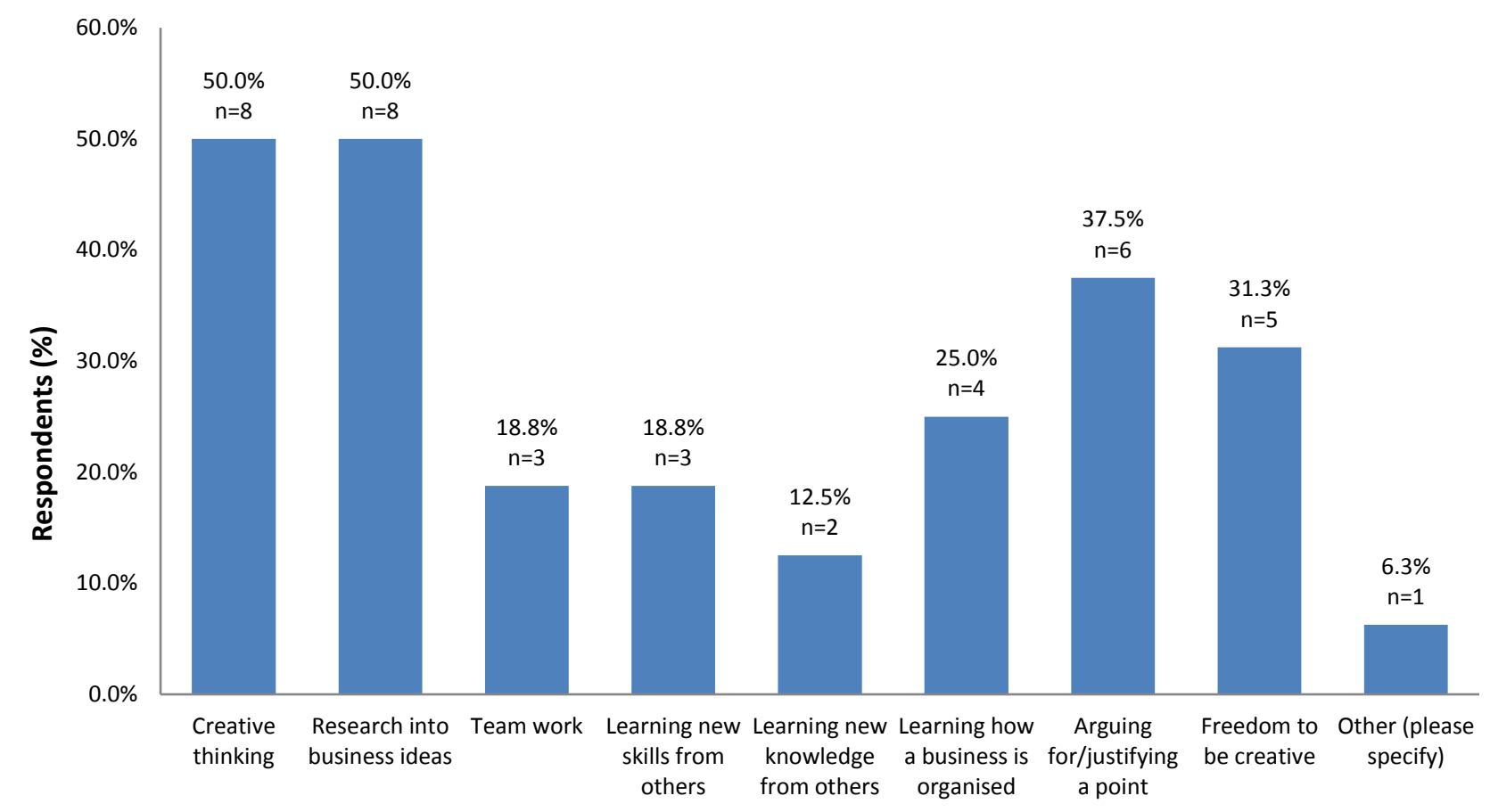

Aspect Enjoyed

Figure 4 When you completed the assignment on $\mathrm{CH} 6005 / \mathrm{CH} 6009$ which aspects did you enjoy the most? (Total $n=16$ )

Although only $18.8 \%$ of students enjoyed the team work element of the assignment they recognised that it is a skill that is sought after in the chemical and pharmaceutical industry (Figure 3). Therefore perhaps more work needs to be done on ensuring the focus of group work lies in engaging students to understand that they need to share responsibility for the team. There is a stronger focus in industry on working in multidisciplinary collaborative teams in order to tackle some of the modern global challenges that we face (e.g. pollution, global warming). A study carried out by Amadel suggested that multi-disciplinary team work is an area that HE institutes need to embed within their courses (Amadel, 2011).

\section{Conclusion}

University curriculums often focus heavily on discipline-specific knowledge and employability can sometimes be viewed as an "add on feature" usually administered through a central university department. The assignment discussed here provided students with an opportunity to think creatively to meet a business need and allowed them to get some experience of working in a multi- disciplinary However, as the students were unfamiliar with being provided with an opportunity for freedom in thinking and demonstrating business acumen they spent too much time being fixated on actual results, and struggled with grasping the concept of communicating an idea on paper. The cohort however, enjoyed being giving the opportunity to research new ideas and apply their discipline-specific knowledge. However evidence suggests that these opportunities for learning should be provided throughout each year of a degree to reinforce the importance of these topics.

\section{References}

ACS taskforce review- George Whitesides \& Joseph Francisco "Entrepreneurship + Innovation = Jobs", https://www.acs.org/content/dam/acsorg/polic y/publicpolicies/innovation/innovation/innovati on.pdf

Amadel, B. (2011) Engineering for the developing world - engineering challenges. National Academy of Engineering, Washington DC, USA. (Last accessed 23 August

2017). 
Incorporating Entrepreneurship skills into Chemistry and Related Curriculums

www.engineeringchallenges.org/cms/7126/73 $\underline{56 . a s p x}$

Andrews, J., \& Higson, H. (2008), Graduate employability, 'soft skills' versus 'hard' business knowledge: a European study. Higher Education in Europe, (33), 4. DOI: $10.1080 / 03797720802522627$

BIS (2013) International Comparative Performance of the UK Research Base, a report for the Department of Business, Innovation \& Skills (BIS) BIS/13/1297. https://www.gov.uk/government/publications/p erformance-of-the-uk-research-baseinternational-comparison-2013

BIS (2016) Wakeham Review of STEM Degree Provision and Graduate Employability. An independent review of science, technology, engineering and maths (STEM) degree provision and graduate employability. IND/16/6.

https://www.gov.uk/government/publications/s tem-degree-provision-and-graduateemployability-wakeham-review

Chell, E. (2013) Review of skill and the entrepreneurial process. International Journal of Entrepreneurial Behaviour and Research, 19, (1), pp 6-31.

DOI: $10.1108 / 13552551311299233$

HEFCE (2016) Higher Education - Business and Community Interaction Survey 2014-15. http://www.hefce.ac.uk/pubs/year/2016/20161 9l

HM Government (2017) Building our Industrial Strategy: Green Paper January 2017. https://beisgovuk.citizenspace.com/strategy/in dustrial-

strategy/supporting documents/buildingourind ustrialstrategygreenpaper.pdf
Kerr, S., \& Runquist, O. (2005) Are We Serious about Preparing Chemists for the 21st Century Workplace or Are We Just Teaching Chemistry? Journal of Chemical Education, 82. DOI: 10.1021/ed082p231

Lowden, K., Hall, S., Elliot, D., \& Lewin, J. (2011) Employers' Perceptions of the Employability Skills of New Graduates, Edge Foundation, London.

O'Leary, S. (2012) Impact Of Entrepreneurship Teaching In Higher Education On The Employability Of Scientists And Engineers. Industry \& Higher Education, (26), 6, pp 431-442.

DOI: 10.5367/ihe.2012.0128

Rae, D. (2007) Connecting enterprise and graduate employability: challenges to the higher education culture and curriculum? Education and Training, (49), 8/9, pp 605619. DOI: $10.1108 / 00400910710834049$

Rae, D. (2008) Riding out the storm: graduates, enterprise and careers in turbulent economic times. Education and Training, (50), 8/9, pp 748-763.

DOI: $10.1108 / 00400910810917118$

Rae, D. (2010) Universities and enterprise education: responding to the challenges of the new era. Journal of Small Business and Enterprise Development, (17), 4, pp 66-81. DOI: $10.1108 / 14626001011088741$

Schofield, P. (1996) A range of skills will pave the way to a job. The Independent, Section 2, 11 July 1996.

Windsor, S.A.M., Rutter, K., McKay, D.M. \& Meyers, N. (2014) Embedding Graduate Attributes at the Inception of a Chemistry Major in a Bachelor of Science. Journal of Chemical Education, 91, 12.

DOI: $10.1021 /$ ed5001526 